\title{
Electrochemical Performance of Carbon derived from Bamboo Shoot as Anode Materials for Lithium-ion Battery
}

\author{
Zhengping Zhao ${ }^{1,2}$, Sitao Shen ${ }^{2}$, Yuting Lit ${ }^{2}$, Qiaodian Chen ${ }^{1}$, Mingqiang Zhong ${ }^{2}$ and Xiufang Chen ${ }^{3, *}$ \\ ${ }^{1}$ Zhijiang College, Zhejiang University of Technology, Hangzhou, 310014, China \\ ${ }^{2}$ College of Materials Science and Engineering, Zhejiang University of Technology, Hangzhou \\ 310014, China \\ ${ }^{3}$ College of Materials Science and Engineering, Zhejiang University of Science and Technology, \\ Hangzhou 310018, China \\ "E-mail: chenxf@zstu.edu.cn
}

doi: $10.20964 / 2020.05 .52$

Received: 5 January 2020 / Accepted: 10 February 2020 / Published: 10 April 2020

Renewable bamboo shoot is carbonized and used as anode material for lithium ion battery to study its electrochemical properties. The average pore diameter of the carbon micropores of the bamboo shoot powder is $19-20 \mathrm{~nm}$, the specific area is as high as $1126.18 \mathrm{~m}^{2} / \mathrm{g}$ and can be controlled by the carbonization temperature. When the current density is $1.0 \mathrm{Ag}^{-1}$, the unit capacitance is $575 \mathrm{mAh} / \mathrm{g}$ and the specific capacity retention rate is $78.2 \%$ after charging and discharging 50 times. After processing, bamboo shoot carbon has the equivalent specific capacity of petroleum carbon materials for market sale, which provides a new idea for the development and utilization of bamboo industry.

Keywords: Bamboo shoot, Carbonization, Anode Materials, Electrochemical properties

\section{FULL TEXT}

(C) 2020 The Authors. Published by ESG (www.electrochemsci.org). This article is an open access article distributed under the terms and conditions of the Creative Commons Attribution license (http://creativecommons.org/licenses/by/4.0/). 